\title{
Fitness level and body composition indices: cross- sectional study among Malaysian adolescent
}

\author{
Redzal Abu Hanifah ${ }^{1,2^{*}}$, Hazreen Abdul Majid ${ }^{3}$, Muhammad Yazid Jalaludin ${ }^{4}$, Nabilla Al-Sadat ${ }^{3}$, Liam J Murray ${ }^{5}$, \\ Marie Cantwell ${ }^{5}$, Tin Tin Su${ }^{3}$, Azmi Mohamed Nahar ${ }^{1,2}$ \\ From International Research Symposium on Population Health 2013 \\ Kuala Lumpur, Malaysia. 18-22 November 2013
}

\begin{abstract}
Background: The importance of fitness level on the well-being of children and adolescent has long been recognised. The aim of this study was to investigate the fitness level of school-going Malaysian adolescent, and its association with body composition indices.

Methods: 1071 healthy secondary school students participated in the fitness assessment for the Malaysian Health and Adolescents Longitudinal Research Team (MyHEART) study. Body composition indices such as body mass index for age, waist circumference and waist height ratio were measured. Fitness level was assessed with Modified Harvard Step Test. Physical Fitness Score was calculated using total time of step test exercise and resting heart rates. Fitness levels were divided into 3 categories - unacceptable, marginally acceptable, and acceptable. Partial correlation analysis was used to determine the association between fitness score and body composition, by controlling age, gender, locality, ethnicity, smoking status and sexual maturation. Multiple regression analysis was conducted to determine which body composition was the strongest predictor for fitness.
\end{abstract}

Results: $43.3 \%$ of the participants were categorised into the unacceptable fitness group, $47.1 \%$ were considered marginally acceptable, and $9.6 \%$ were acceptable. There was a significant moderate inverse association $(p<0.001)$ between body composition with fitness score $(r=-0.360,-0.413$ and -0.403 for body mass index for age, waist circumference and waist height ratio, respectively). Waist circumference was the strongest and significant predictor for fitness ( $B=-0.318, p=0.002$ ).

Conclusion: Only $9.6 \%$ of the students were fit. There was also an inverse association between body composition and fitness score among apparently healthy adolescents, with waist circumference indicated as the strongest predictor. The low fitness level among the Malaysian adolescent should necessitate the value of healthy lifestyle starting at a young age.

\section{Background}

Physical activity relates to any movement produced by the individual's skeletal muscles that results in energy expenditure [1]. Physical fitness is a set of attributes a person have or achieve, [1] which is linked to the person's capability to do physical activity [2]. Fitness is divided into health and skill related components, with the health component further consists of cardiorespiratory endurance, muscular

\footnotetext{
* Correspondence: docredzal@gmail.com

'Department of Sports Medicine, University Malaya Medical Centre, 59100 Kuala Lumpur, Malaysia

Full list of author information is available at the end of the article
}

endurance, muscular strength, and flexibility [1]. An individual who is physically fit has the ability to do daily activities with vigour and alertness, without undue fatigue and still has enough energy to pursue leisure-time activities and prepare for emergencies that ensue [3].

In healthy adults, studies have shown that cardiorespiratory fitness is inversely associated with all-cause mortality and cardiovascular disease [4-6]. Low fitness levels and childhood obesity has been shown to continue into adulthood, with consequent health morbidity like cardiovascular and metabolic diseases [7].In adolescent, most commonly used measurements for adiposity are body 
mass index (BMI), waist circumference (WC), and waist height ratio (WHtR). BMI [8-10], WC [11-13] and WHtR [14-16] are strong predictors for cardio-metabolic risk factors in the paediatric population.

The previous studies that investigated the association between fitness and body composition indices in adolescent [17-20] used parameters such as BMI or WC. There are no studies that investigate these indices with WHtR, or determine which of the body composition indices in adolescent is the strongest predictor for fitness. This is of clinical interest for the purpose of mass screening and future population based health intervention.

In Malaysia, there are limited community based studies determining the fitness level among adolescent. A few used physical activity questionnaire to determine the physical activity level $[21,22]$. In this cross sectional study, we investigated the fitness level among Malaysian adolescent using step test. We determined the association between BMI, WC and WHtR to the fitness level and identified which body composition indices is the strongest predictor of fitness.

\section{Methods}

\section{Study population}

The Malaysian Health and Adolescents Longitudinal Research Team (MyHEART) is an on- going prospective longitudinal cohort study in Malaysia. The first phase (MyHEART I 2012) involved Form 1 students (13 years old) from 15 rural and urban secondary schools randomly selected in three states - Perak, Selangor and Kuala Lumpur. The study lasted for three months from March till May 2012.

Study design, sampling methods, data collection protocols and inclusion and exclusion criteria have been reported elsewhere [23]. Ethical approval which complied with the International Conference on Harmonization Guidelines for Good Clinical Practice (ICH-GCP) and the Declaration of Helsinki was obtained from the Medical Ethics Committee of the University of Malaya Medical Centre, Malaysia (IRB number 896.34).Both written consent from parents and agreement forms from participants were obtained prior to the study.

\section{Anthropometric and clinical data}

The participants completed a standardised form, which socio-demographic data such as date of birth, age, gender, and ethnicity were collected. Systolic and diastolic blood pressures were measured with a stethoscope and mercurial sphygmomanometer (CK-101C, Spirit Medical Co., Taiwan).The participants sit upright with the right upper arm on the table at the level of the heart. They rested for 5 minutes prior to measurement. Pulse rate was obtained with a finger pulse oximeter (Baseline 12-1926 Fingertip Pulse Oximeter, Fabrication Enterprises Inc., USA).
Height was measured using a stadiometer (Seca Portable 217 Seca, UK) and recorded to the nearest $0.1 \mathrm{~cm}$. Weight was measured with a digital electronic weighing scale (Seca 813, Seca, UK) and recorded to the nearest 0.1 kilogram. BMI was calculated by using weight in kilograms divided by the square of height in meters. BMI standard deviation (BMI SD) for age and gender was calculated using the World Health Organisation (WHO) Anthro Software version 3.2.2 for SPSS macro, based on WHO reference 2007 (WHO,Geneva, Switzerland). WC was measured with a non-elastic measuring tape (Seca 201, Seca, UK) mid-point between the lowest rib margin and the iliac crest, and recorded to the nearest millimetre. WHtR was determined by $\mathrm{WC}$ in $\mathrm{cm}$ divided by height in $\mathrm{cm}$.

Sexual maturation was based on self-reported Tanner staging questionnaire[24]. External genitalia development and pubic hair in boys, and breast development and pubic hair in girls were used for Tanner staging.

\section{Fitness test}

Fitness test was conducted using the modified Harvard Step Test $[25,26]$. It utilized a $30 \mathrm{~cm}$ high step box which was readily available for fitness assessment in all secondary schools in Malaysia. A finger pulse oxymeter was attached to one of the fingers to continuously monitor the pulse rate and oxygen saturation $\left(\mathrm{SpO}_{2}\right)$. With a metronome set at 120 beats per minute, the participants stepped on and off the box with both feet for 5 minutes. Those with heart rates above 200 beats per minute, had difficulty in breathing, $\mathrm{SpO}_{2}$ less than $90 \%$ or unable to finish, were stopped immediately. Once the participants have completed the step test or were stopped due to the aforementioned reasons, they quickly sit down on the box and rest. Heart rates at 0,1 and 2 minutes of rest were recorded, as well as total duration of exercise in seconds. The fitness test was conducted under close supervision of a sports physician.

Physical fitness score (PFS) was calculated by the total duration of exercise in seconds $\times 100$ and divided with the sum of three heart rates at 0,1 and 2 minutes of rest. PFS $<55$ is considered poor, 55 - 64 as low average, $65-79$ as high average, $80-89$ as good, and $>90$ as excellent. The medium score (65-79) was used as a cut- off point to separate the participants of upper and lower PFS, thus $<65$ is considered unacceptable, 65-79 as marginally acceptable, and $>80$ as acceptable $[25,26]$.

\section{Statistical analysis}

Test for normality was conducted for continuous variables. Analysis was done separately by gender. Mean \pm SD was calculated for both baseline characteristics and exercise values. Independent $t$-test and chi square test were used where appropriate to compare between gender differences. 
Partial correlation coefficient was used to examine the direction and strength between body composition indices with PFS, with controlling of factors - age and dummy coded gender, locality (urban/rural), smoking status, Tanner staging and ethnicity. Multiple regression analysis was performed to determine the strongest body composition predictor for PFS, with the same controlling factors stated. All statistical analyses were completed using SPSS version 20 and the level of significance at $\mathrm{p}<0.05$.

\section{Results}

\section{Descriptive statistics}

1361 students participated in the MyHEART study. However, 285 participants refused to be involved in the exercise test, while five were excluded due to illness or with pre-existing medical condition. Thus, PFS data was available from 1071 participants.

Table 1 and table 2 present the baseline characteristics and exercise parameters of the participants. Boys had a significantly higher WC and WHtR ( $<$ 0.001) compared to girls. No significant difference for BMI and BMI SD in both genders. Boys had a higher mean PFS than girls (71.2 \pm 13.1 vs. $61.1 \pm 12.5, \mathrm{p}<0.001)$. When we further categorize the PFS (Figure 1), only $9.6 \%$ of the participants were in the acceptable range, with $21.8 \%$ of boys and $1.9 \%$ of girls. $47.1 \%$ were marginally acceptable $(55.9 \%$ of boys, $41.7 \%$ of girls) and $43.3 \%$ were in the unacceptable fitness level ( $22.3 \%$ of boys, $56.4 \%$ of girls).

Table 1 Baseline characteristics of participants.

\begin{tabular}{|c|c|c|c|}
\hline & Boys & Girls & $p$ \\
\hline n & 405 & 666 & - \\
\hline Ethnicity (\%) & & & 0.87 \\
\hline Malay & 82.3 & 83.0 & \\
\hline Chinese & 8.2 & 7.0 & \\
\hline Indian & 6.5 & 7.1 & \\
\hline Others & 3.1 & 2.8 & \\
\hline Tanner staging (\%) & & & $<0.001$ \\
\hline 1 & 8.2 & 4.8 & \\
\hline 2 & 30.5 & 18.2 & \\
\hline 3 & 40.8 & 48.4 & \\
\hline 4 & 17.7 & 25.3 & \\
\hline 5 & 2.9 & 3.4 & \\
\hline Age (years) & $12.8 \pm 0.3$ & $12.9 \pm 0.3$ & 0.024 \\
\hline Pulse rate (beats/min) & $85.5 \pm 14.0$ & $90.1 \pm 13.2$ & $<0.001$ \\
\hline $\mathrm{SBP}(\mathrm{mm} / \mathrm{Hg})$ & $110.6 \pm 10.5$ & $108.7 \pm 11.8$ & 0.006 \\
\hline $\mathrm{DBP}(\mathrm{mm} / \mathrm{Hg})$ & $68.8 \pm 10.5$ & $66.7 \pm 10.3$ & 0.001 \\
\hline BMI $\left(\mathrm{kg} / \mathrm{m}^{2}\right)$ & $19.8 \pm 5.0$ & $19.7 \pm 4.4$ & 0.729 \\
\hline BMI SD & $0.17 \pm 1.7$ & $0.02 \pm 1.4$ & 0.130 \\
\hline WC $(\mathrm{cm})$ & $70.5 \pm 13.1$ & $67.5 \pm 9.9$ & $<0.001$ \\
\hline WHtR & $0.47 \pm 0.1$ & $0.45 \pm 0.1$ & $<0.001$ \\
\hline
\end{tabular}

Data are mean \pm SD or percentage, $\mathrm{SBP}=$ Systolic blood pressure, $\mathrm{DBP}=$ Diastolic blood pressure, BMI = Body mass index, WC = Waist circumference, $\mathrm{WH} \mathrm{tR}=$ Waist height ratio.
Table 2 Exercise parameters of participants.

\begin{tabular}{llll}
\hline & Boys & Girls & $\boldsymbol{p}$ \\
\hline Pulse rate at 0 min rest (beats/min) & $171.4 \pm 17.8$ & $180.2 \pm 15.2$ & $<0.001$ \\
Pulse rate at $1 \mathrm{~min}$ rest (beats/min) & $125.8 \pm 19.8$ & $144.4 \pm 15.7$ & $<0.001$ \\
Pulse rate at 2 min rest (beats/min) & $115.0 \pm 17.5$ & $131.1 \pm 14.6$ & $<0.001$ \\
Total duration of exercise (s) & $289.8 \pm 40.0$ & $277.6 \pm 54.2$ & $<0.001$ \\
PFS (mean) & $71.2 \pm 13.1$ & $61.1 \pm 12.5$ & $<0.001$ \\
PFS (\%) & & & $<0.001$ \\
Unacceptable & 22.3 & 56.4 & \\
Marginally acceptable & 55.9 & 41.7 & \\
Acceptable & 21.8 & 1.9 & \\
\hline
\end{tabular}

Data are mean \pm SD or percentage, PFS= Physical fitness score

\section{Correlation analysis and multiple linear regression analysis}

Correlation analysis in Table 3 showed BMI SD, WC and WHtR were moderately inverse correlated with PFS ( $\mathrm{r}=$ $-0.360, \mathrm{r}=-0.413$ and $\mathrm{r}=-0.403$ respectively, $\mathrm{p}<0.001$ ). The strongest correlation was with WC. Multiple regression analysis in Table 4 showed that $\mathrm{WC}$ was the only significant predictor for PFS $(\beta=-0.318, \mathrm{p}=0.002)$.

\section{Discussion}

Fitness level

This study showed that only $9.6 \%$ of Malaysian adolescent were considered fit (acceptable range) after the step test. The ratio of fitness for girls to boys was more than $1: 10$ ( $1.9 \%$ and $21.8 \%$ respectively). The low level of fitness among the study group emphasizes the need to identify and instil healthy lifestyle choices from young. Other Malaysian studies have shown that between $3 \%-20 \%$ of adolescent had high levels of physical activity, $50 \%-61.5 \%$ were moderately active and $30 \%-35.3 \%$ had low physical activity levels $[21,22]$. However, these studies were carried out only in schools of one district in a Malaysian state. Moreover, the result was based on physical activity questionnaire, which assessed reported behaviours of the participants, while the current study objectively assessed the fitness level of adolescent.

Our result also showed that boys were fitter than girls. This was in accordance to other adolescent population in Asian countries [27-29], Europe [20,30,31] and North America [32,33]. Gender difference of fitness level could be due to variances in haematological parameters and ventricular chamber sizes [34,35].

This low level of fitness is a global problem. Based on analysis of 50 studies involving 25 million children from 28 countries spanning from 1964-2010, our current children generation were $15 \%$ less fit than when their parents were at their age [36]. Low fitness level in the paediatric population is associated with higher risk of a cluster of cardio-metabolic risk factors [31,37-39]. Various studies have shown the benefits of intervention programs in improving 


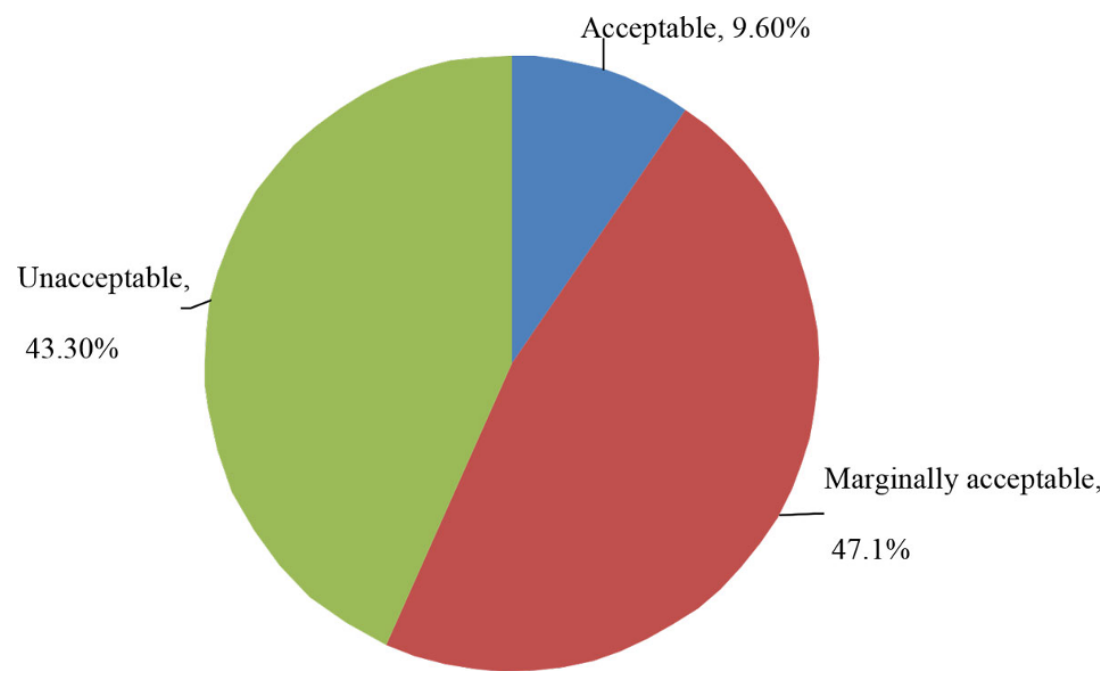

Figure 1 Physical Fitness Score (PFS) of participants.

Table 3 Correlation coefficient $(r)$ between body composition indices and physical fitness score using partial correlation analysis*

\begin{tabular}{lll}
\hline Body composition & \multicolumn{2}{l}{ Physical fitness score } \\
\hline BMI SD & $\boldsymbol{r}$ & $\boldsymbol{p}$ \\
WC (cm) & -0.360 & $<0.001$ \\
WHtR & -0.413 & $<0.001$ \\
\end{tabular}

$\mathrm{BMI}=$ Body mass index, $\mathrm{WC}=$ Waist circumference, $\mathrm{WHtR}=$ Waist height ratio ${ }^{*}$ Control for age, gender, smoking status, ethnicity, locality and sexual maturity

Table 4 Standardised coefficient (ß) between body composition indices and physical fitness score using multiple regression analysis*

\begin{tabular}{lll}
\hline Body composition & \multicolumn{2}{l}{ Physical fitness score } \\
\hline & $\boldsymbol{B}$ & $\boldsymbol{p}$ \\
\hline BMI SD & -0.007 & NS \\
WC $(\mathrm{cm})$ & -0.318 & 0.002 \\
WHtR & -0.067 & NS
\end{tabular}

NS = Not significant, BMI = Body mass index,$W C=$ Waist circumference, $\mathrm{WH} \mathrm{tR}=$ Waist height ratio

*Control for age, gender, smoking status, ethnicity, locality and sexual maturity

children's and adolescent's health status i.e. reduce body fat [40-43], improve metabolic syndrome score [44,45], positive effect on blood pressure [46,47], increase bone density $[48,49]$ and academic performances $[50,51]$.

\section{Body composition indices and fitness}

This study showed that BMI SD, WC and WHtR were all inversely correlated with fitness level. Our result was similar with findings from other studies [17-20]. Another study also showed that visceral adipose tissue measured with abdomen MRI was inversely correlated with aerobic fitness [52].Moreover, our study also investigated the correlation with WHtR, which is also considered as a marker of intra-abdominal adiposity in children and adolescent [53]. WHtR was shown to be a good predictor of cardio-metabolic risk factors [14-16].

WC was the strongest predictor to fitness in our findings. This reiterates the importance of $\mathrm{WC}$ as a measurement tool of health status for adolescent. It is a surrogate marker for intra-abdominal adiposity [54], and a strong predictor for cardio-metabolic risk factors in children and adolescent [11-13]. The actual relation of WC on cardio-metabolic risk factors is still unclear. A few possible hypotheses have been proposed. Intraabdominal adiposity is an indicator of impaired energy storage regulation, which leads to an excess of fat collection in the liver, and subsequent compromised liver function of fat regulation. Thus, increased intra-hepatic fat storage consequently leads to dyslipidaemia and insulin resistance [55]. Another probable way is the release of free fatty acids through lipolysis of omentum and mesenteric adipocytes, which in turn triggers insulin resistance and hypercholesterolemia [56].

Other studies have investigated the influence of fitness on adiposity indices using multiple linear regression analysis. In one study, fitness was determined to be an independent predictor $\mathrm{WC}$, visceral and abdominal subcutaneous adipose tissue after adjusting factors of age, gender, sexual maturity and BMI [17]. Another showed that $\mathrm{VO}_{2} \mathrm{max}$, a marker of fitness, was inversely associated with both BMI and WC after controlling factors of age, sexual maturity and active commuting to school 
[19]. Interestingly, it showed that adolescent with low fitness level were associated with increased $5.6 \mathrm{~cm}$ and $2.9 \mathrm{~cm}$ of waist circumference in boys and girls respectively, as compared to those in the higher fitness level. A third study in Spain revealed cardiorespiratory fitness was the strongest predictor of BMI, sum of skinfold thickness and subcutaneous truncal fat, as compared to physical activity level [57]. All these warrant the importance of active intervention and healthy lifestyle to start at a young age.

American College of Sports Medicine recommends daily moderate to vigorous intensity aerobic exercise for $\geq 60$ minutes per day for children [2]. Three hours per week sports participation has shown to reduce body fat and increase fitness level among boys [58]. $\mathrm{A} \mathrm{VO}_{2} \max$ of $45 \mathrm{ml} / \mathrm{kg} / \mathrm{min}$ for boys and $40.7 \mathrm{ml} / \mathrm{kg} / \mathrm{min}$ for girls may be the minimum level to limit accumulation of intra-abdominal adiposity [19].

School based intervention programs in Malaysia showed positive effects on fitness and flexibility [59]. However, these studies included additional physical activity programs on top of the compulsory physical education classes. Future studies are needed to investigate the implication of physical education classes on Malaysian adolescent's health status.

\section{Strength and limitation}

The strength of our study is the large sample of participants. To our knowledge, this is the first large crosssectional study in Malaysia to determine the fitness level among school-going adolescent. This study utilized modified Harvard step test as a tool for fitness assessment, which does not require large space to conduct, minimal equipment and expertise, and a short duration of time to complete (less than 10 minutes). Further studies are needed to compare this step test with other fitness protocols.

There are limitations to this study. Cross-sectional design cannot capture cause-effect relationship. The cohort sample are of the same age group, thus this does not reflect the whole adolescent population. More than $80 \%$ of participants were Malays, which do not reflect the racial composition of Malaysian adolescent. However this study is still of importance since it is one of a few that assessed fitness level. Our next step would be in MyHEART II 2014 where a follow-up of the same participants would be conducted, thus a longitudinal association between body composition indices with fitness and changes in fitness level could be determined.

\section{Conclusions}

This study showed only $9.6 \%$ of Malaysian adolescent were categorised as fit, with ratio of girls to boys of 1:10. BMI $\mathrm{SD}, \mathrm{WC}$ and WHtR were inversely correlated with fitness, and $\mathrm{WC}$ was the strongest predictor for fitness. The importance of being physically active and fit needs to be emphasized by all stake-holders and nurture healthy lifestyle choices for the young.

\section{List of abbreviations used}

MyHEART: Malaysian Health and Adolescents Longitudinal Research Team; BMl: Body mass index; WC: Waist circumference; WHtR: Waist height ratio; ICH-GCP: International conference on harmonization - guidelines for good clinical practice; $\mathrm{SpO}_{2}$ : Oxygen saturation; SD: Standard deviation; WHO: World health organization; PFS: Physical fitness score.

\section{Competing interests}

The authors declare that they have no competing interests.

\section{Authors' contributions}

All authors contribute to study design, revising and improving the manuscript; RAH, NAAM, MYJ, HAM and TTS were involved in field work and data collection; RAH, MNAM, HAM, LM, MC and TTS participated in analysis and interpretation of data; RAH drafted the manuscript.

\section{Acknowledgements}

This study was supported by grants from University of Malaya Research Grant (RG299-11HTM) and Vice Chancellor Research Grant (UMQUB3D-2011). The post-doctoral research fellow position for this project was jointly funded by University of Malaya and Queen's University of Belfast. The funders had no role in study design, collection, analysis and interpretation of data, writing of manuscript, or decision to submit for publication. We would like to thank all the enumerators who helped us throughout data collection. We are also grateful for the support and guidance provided by the Centre of Population Health, University of Malaya and the Centre of Public Health, Queen's University Belfast.

This article has been published as part of BMC Public Health Volume 14 Supplement 3, 2014: Proceedings of the International Research Symposium on Population Health 2013. The full contents of the supplement are available online at http://www.biomedcentral.com/bmcpublichealth/ supplements/14/S3. Publication charges for this supplement were funded by the University of Malaya.

\section{Authors' details}

${ }^{1}$ Department of Sports Medicine, University Malaya Medical Centre, 59100 Kuala Lumpur, Malaysia. ${ }^{2}$ Sports Medicine Unit, Faculty of Medicine, University Malaya, 50603 Kuala Lumpur, Malaysia. ${ }^{3}$ Centre for Population Health (CePH), Department of Social and Preventive Medicine, Faculty of Medicine, University Malaya, 50603 Kuala Lumpur, Malaysia. ${ }^{4}$ Department of Paediatrics, Faculty of Medicine, University Malaya, 50603 Kuala Lumpur, Malaysia. ${ }^{5}$ Centre for Public Health, Queens University Belfast, Royal Victoria Hospital, Grosvenor Road, Belfast, Northern Ireland, UK.

Published: 24 November 2014

\section{References}

1. Caspersen CJ, Powell KE, Christenson GM: Physical activity, exercise, and physical fitness: definitions and distinctions for health-related research. Public Health Rep 1985, 100(2):126-131.

2. Pescatello L, American College of Sports Medicine: ACSM's guidelines for exercise testing and prescription Philadelphia: Wolters Kluwer/Lippincott Williams \& Wilkins Health; 2014.

3. Clarke H: Phycial Fitness Research Digest Series 1 Number 1 Washington, DC: President's Council on Physical Fitness and Sports; 1971.

4. Laukkanen JA, Rauramaa R, Salonen JT, Kurl S: The predictive value of cardiorespiratory fitness combined with coronary risk evaluation and the risk of cardiovascular and all-cause death. J Intern Med 2007, 262(2):263-272.

5. Laukkanen JA, Rauramaa R, Kurl S: Exercise workload, coronary risk evaluation and the risk of cardiovascular and all-cause death in middleaged men. Eur J Cardiovasc Prev Rehabil 2008, 15(3):285-292.

6. Aijaz B, Babuin L, Squires RW, Kopecky SL, Johnson BD, Thomas RJ, Allison TG: Long-term mortality with multiple treadmill exercise test 
abnormalities: comparison between patients with and without cardiovascular disease. Am Heart J 2008, 156(4):783-789.

7. Velasquez-Mieyer P, Perez-Faustinelli S, Cowan PA: Identifying Children at Risk for Obesity, Type 2 Diabetes, and Cardiovascular Disease. Diabetes Spectr 2005, 18(4):213-220.

8. Freedman DS, Khan LK, Dietz WH, Srinivasan SR, Berenson GS: Relationship of childhood obesity to coronary heart disease risk factors in adulthood: the Bogalusa Heart Study. Pediatrics 2001, 108(3):712-718.

9. Agirbasli $\mathrm{M}$, Agaoglu NB, Ergonul O, Yagmur I, Aydogar $\mathrm{H}$, Oneri $\mathrm{T}$, Ozturk O: Comparison of anthropometric indices in predicting metabolic syndrome components in children. Metab Syndr Relat Disord 2011, 9(6):453-459.

10. Kim C, Kim B, Joo N, Park Y, Lim H, Ju Y, Yang S, Park S, Cho B, Park K: Determination of the BMl threshold that predicts cardiovascular risk and insulin resistance in late childhood. Diabetes Res Clin Pract 2010, 88(3):307-313.

11. Lee JM, Davis MM, Woolford SJ, Gurney JG: Waist circumference percentile thresholds for identifying adolescents with insulin resistance in clinical practice. Pediatr Diabetes 2009, 10(5):336-342.

12. Meng L, Luo N, Mi J: Impacts of types and degree of obesity on nonalcoholic fatty liver disease and related dyslipidemia in Chinese schoolage children? Biomed Environ Sci 2011, 24(1):22-30.

13. Johnson ST, Kuk JL, Mackenzie KA, Huang TT, Rosychuk RJ, Ball GD: Metabolic risk varies according to waist circumference measurement site in overweight boys and girls. J Pediatr 2010, 156(2):247-252 e241.

14. Goulding A, Taylor RW, Grant AM, Parnell WR, Wilson NC, Williams SM: Waist-to-height ratios in relation to BMI z-scores in three ethnic groups from a representative sample of New Zealand children aged 5-14 years. Int J Obes 2010, 34(7):1188-1190.

15. Mokha JS, Srinivasan SR, Dasmahapatra P, Fernandez C, Chen W, Xu J, Berenson GS: Utility of waist-to-height ratio in assessing the status of central obesity and related cardiometabolic risk profile among normal weight and overweight/obese children: the Bogalusa Heart Study. BMC Pediatr 2010, 10:73.

16. Schwandt P, Bertsch T, Haas GM: Anthropometric screening for silent cardiovascular risk factors in adolescents: The PEP Family Heart Study. Atherosclerosis 2010, 211(2):667-671.

17. Lee SJ, Arslanian SA: Cardiorespiratory fitness and abdominal adiposity in youth. Eur J Clin Nutr 2007, 61(4):561-565.

18. Brunet M, Chaput JP, Tremblay A: The association between low physical fitness and high body mass index or waist circumference is increasing with age in children: the 'Quebec en Forme' Project. Int J Obes 2007, 31(4):637-643.

19. Ortega FB, Tresaco B, Ruiz JR, Moreno LA, Martin-Matillas M, Mesa JL, Warnberg J, Bueno M, Tercedor P, Gutierrez A, et al: Cardiorespiratory fitness and sedentary activities are associated with adiposity in adolescents. Obesity 2007, 15(6):1589-1599.

20. Hussey J, Bell C, Bennett K, O'Dwyer J, Gormley J: Relationship between the intensity of physical activity, inactivity, cardiorespiratory fitness and body composition in 7-10-year-old Dublin children. Br J Sports Med 2007, 41(5):311-316.

21. Dan SP, Mohd Nasir MT, Zalilah MS: Sex and ethnic differentials in physical activity levels of adolescents in kuantan. Malays J Nutr 2007, 13(2):109-120.

22. Hashim HA, Golok F, Ali R: Profiles of exercise motivation, physical activity, exercise habit, and academic performance in Malaysian adolescents: A cluster analysis. Int I Collab Res Internal Med Public Health 2011, 3(6):416-428.

23. Abu Hanifah R, Mohamed MNA, Jaafar Z, Abdul Mohsein NA-S, MY J: The Correlates of Body Composition with Heart Rate Recovery after Step Test: An Exploratory Study of Malaysian Adolescents. PloS one 2013, 8(12):e82893.

24. Tanner JM, Whitehouse RH: Clinical longitudinal standards for height, weight, height velocity, weight velocity, and stages of puberty. Arch Dis Child 1976, 51(3):170-179.

25. Trevino RP, Marshall RM, Hale DE, Rodriguez R, Baker G, Gomez J: Diabetes risk factors in low-income Mexican-American children. Diabetes care 1999, 22(2):202-207.

26. Trevino RP, Fogt DL, Wyatt TJ, Leal-Vasquez L, Sosa E, Woods C: Diabetes risk, low fitness, and energy insufficiency levels among children from poor families. J Am Diet Assoc 2008, 108(11):1846-1853.
27. Gonzalez-Suarez CB, Lee-Pineda K, Zamora MTG, Sibug EO, Velasco ZF, Grimmer-Somers K: Cardiovascular Fitness and Caloric Intake in Filipino Obese Children: An Observational Study. Asian Journal of Clinical Nutrition 2012 2012, 4(3):88-97.

28. Chen $\sqcup$, Fox KR, Haase A, Wang JM: Obesity, fitness and health in Taiwanese children and adolescents. Eur I Clin Nutr 2006, 60(12):1367-1375.

29. Mak KK, Ho SY, Lo WS, Thomas GN, McManus AM, Day JR, Lam TH: Healthrelated physical fitness and weight status in Hong Kong adolescents. BMC public health 2010, 10:88.

30. Ostojic SM, Stojanovic MD, Stojanovic V, Maric J, Njaradi N: Correlation between fitness and fatness in 6-14-year old Serbian school children. $J$ Health Popul Nutr 2011, 29(1):53-60.

31. Ortega FB, Ruiz JR, Hurtig-Wennlof A, Vicente-Rodriguez G, Rizzo NS, Castillo MJ, Sjostrom M: Cardiovascular fitness modifies the associations between physical activity and abdominal adiposity in children and adolescents: the European Youth Heart Study. Br J Sports Med 2010, 44(4):256-262.

32. Burns R, Hannon JC, Brusseau TA, Shultz B, Eisenman P: Indices of abdominal adiposity and cardiorespiratory fitness test performance in middle-school students. J Obes 2013, 2013:912460.

33. Willig AL, Hunter GR, Casazza K, Heimburger DC, Beasley TM, Fernandez JR: Body fat and racial genetic admixture are associated with aerobic fitness levels in a multiethnic pediatric population. Obesity 2011, 19(11):2222-2227.

34. Turley KR: Cardiovascular responses to exercise in children. Sports Med 1997, 24(4):241-257.

35. Rowland $T$, Goff $D$, Martel $L$, Ferrone $L$ : Influence of cardiac functional capacity on gender differences in maximal oxygen uptake in children. Chest 2000, 117(3):629-635

36. Tomkinson GR, Annandales M, Ferrar K: Global Changes in Cardiovascular Endurance of Children and Youth Since 1964: Systematic Analysis of 25 Million Fitness Test Results from 28 Countries [abstract]. Circulation 2013, 128:A13498.

37. Ruiz JR, Rizzo NS, Ortega FB, Loit HM, Veidebaum T, Sjostrom M: Markers of insulin resistance are associated with fatness and fitness in school-aged children: the European Youth Heart Study. Diabetologia 2007, 50(7):1401-1408

38. Jimenez-Pavon D, Castillo MJ, Moreno LA, Kafatos A, Manios Y, Kondaki K, Beghin $L$, Zaccaria $M$, de Henauw $S$, Widhalm $K$, et al: Fitness and fatness are independently associated with markers of insulin resistance in European adolescents; the HELENA study. Int I Pediatr Obes 2011, 6(3-4):253-260

39. Eisenmann JC, Welk GJ, Ihmels M, Dollman J: Fatness, fitness, and cardiovascular disease risk factors in children and adolescents. Med Sci Sports Exerc 2007, 39(8):1251-1256.

40. Berkey CS, Rockett HR, Field AE, Gillman MW, Frazier AL, Camargo CA Colditz GA: Activity, dietary intake, and weight changes in a longitudinal study of preadolescent and adolescent boys and girls. Pediatrics 2000, 105(4):E56.

41. Wilks DC, Rank M, Christle J, Langhof H, Siegrist M, Halle M: An inpatient lifestyle-change programme improves heart rate recovery in overweight and obese children and adolescents (LOGIC Trial). Eur J Prev Cardiol 2012

42. Ara I, Vicente-Rodriguez G, Perez-Gomez J, Jimenez-Ramirez J, SerranoSanchez JA, Dorado C, Calbet JA: Influence of extracurricular sport activities on body composition and physical fitness in boys: a 3-year longitudinal study. Int J Obes 2006, 30(7):1062-1071.

43. Hruby A, Chomitz VR, Arsenault LN, Must A, Economos CD, McGowan RJ, Sacheck JM: Predicting maintenance or achievement of healthy weight in children: the impact of changes in physical fitness. Obesity 2012, 20(8):1710-1717.

44. DuBose KD, Eisenmann JC, Donnelly JE: Aerobic fitness attenuates the metabolic syndrome score in normal-weight, at-risk-for-overweight, and overweight children. Pediatrics 2007, 120(5):e1262-1268.

45. Sacheck JM, Kuder JF, Economos CD: Physical fitness, adiposity, and metabolic risk factors in young college students. Med Sci Sports Exerc 2010, 42(6):1039-1044.

46. McMurray RG, Harrell JS, Bangdiwala SI, Bradley CB, Deng S, Levine A: A school-based intervention can reduce body fat and blood pressure in young adolescents. J Adolesc Health 2002, 31(2):125-132. 
47. Danforth JS, Allen KD, Fitterling JM, Danforth JA, Farrar D, Brown M, Drabman RS: Exercise as a treatment for hypertension in lowsocioeconomic-status black children. J Consult Clin Psychol 1990, 58(2):237-239.

48. McKay HA, MacLean L, Petit M, MacKelvie-O'Brien K, Janssen P, Beck T, Khan KM: "Bounce at the Bell": a novel program of short bouts of exercise improves proximal femur bone mass in early pubertal children. Br J Sports Med 2005, 39(8):521-526.

49. MacKelvie KJ, Khan KM, Petit MA, Janssen PA, McKay HA: A school-based exercise intervention elicits substantial bone health benefits: a 2-year randomized controlled trial in girls. Pediatrics 2003, $112(6 \mathrm{Pt}$ 1):e447.

50. Donnelly JE, Lambourne K: Classroom-based physical activity, cognition, and academic achievement. Prev Med 2011, 52(Suppl 1):S36-42.

51. Dwyer T, Sallis JF, Blizzard L, Lazarus R: Relationship of academic performance to physical activity and fitness in children. Pediatr Exerc Sci 2001, 13(3):225-237.

52. Winsley RJ, Armstrong N, Middlebrooke AR, Ramos-lbanez N, Williams CA: Aerobic fitness and visceral adipose tissue in children. Acta Paediatr 2006, 95(11):1435-1438.

53. Haas GM, Liepold E, Schwandt P: Percentile curves for fat patterning in German adolescents. World J Pediatr 2011, 7(1):16-23.

54. Brambilla P, Bedogni G, Moreno LA, Goran MI, Gutin B, Fox KR, Peters DM, Barbeau P, De Simone M, Pietrobelli A: Crossvalidation of anthropometry against magnetic resonance imaging for the assessment of visceral and subcutaneous adipose tissue in children. Int J Obes 2006, 30(1):23-30.

55. Seppala-Lindroos A, Vehkavaara S, Hakkinen AM, Goto T, Westerbacka J, Sovijarvi A, Halavaara J, Yki-Jarvinen H: Fat accumulation in the liver is associated with defects in insulin suppression of glucose production and serum free fatty acids independent of obesity in normal men. $J$ Clin Endocrinol Metab 2002, 87(7):3023-3028.

56. Klein S, Allison DB, Heymsfield SB, Kelley DE, Leibel RL, Nonas C, Kahn R: Waist Circumference and Cardiometabolic Risk: a Consensus Statement from Shaping America's Health: Association for Weight Management and Obesity Prevention; NAASO, the Obesity Society; the American Society for Nutrition; and the American Diabetes Association. Obesity 2007, 15(5):1061-1067.

57. Ara I, Moreno LA, Leiva MT, Gutin B, Casajus JA: Adiposity, physical activity, and physical fitness among children from Aragon, Spain. Obesity 2007, 15(8):1918-1924.

58. Ara I, Vicente-Rodriguez G, Jimenez-Ramirez J, Dorado C, SerranoSanchez JA, Calbet JA: Regular participation in sports is associated with enhanced physical fitness and lower fat mass in prepubertal boys. Int $J$ Obes Relat Metab Disord 2004, 28(12):1585-1593.

59. Rengasamy S: A physical fitness intervention program within a physical education class on selected health-related fitness among secondary school students. Procedia Soc Behav Sci 2012, 55(2012):1104-1112.

doi:10.1186/1471-2458-14-S3-S5

Cite this article as: Hanifah et al:: Fitness level and body composition indices: cross-sectional study among Malaysian adolescent. BMC Public Health 2014 14(Suppl 3):S5.

\section{Submit your next manuscript to BioMed Central and take full advantage of:}

- Convenient online submission

- Thorough peer review

- No space constraints or color figure charges

- Immediate publication on acceptance

- Inclusion in PubMed, CAS, Scopus and Google Scholar

- Research which is freely available for redistribution 